\title{
Особенности состава мегакристов анортита в породах вулкана Малый Тигиль(Срединный хребет, Камчатка) как маркер параметров субдукции
}

\author{
Толстых М.Л. ${ }^{1}$, Бабанский А.Д. ${ }^{2}$ \\ ${ }^{1}$ Институт геохимии и аналитической химии им. В.И. Вернадского PAH, Москва, mashtol@таil.ru \\ ${ }^{2}$ Институт геологии рудных месторождений ИГЕМ РАН, Москва
}

Аннотация. В измененных лавах массива Малый Тигиль, одного из вулканических центров Срединного хребта Камчатки, мегакристы анортита размером до 25 мм. Особенности микроэлементного состава этих фаз позволяют реконструировать геодинамические условия их формирования, в т.ч. глубину кровли субдуцирующей плиты, которая составляет около 150 км. Это позволяет предполагать, что изучаемые породы соответствуют неогеновому этапу вулканизма Срединного хребта Камчатки, когда фронт субдукции располагался западнее его современной позиции.

Ключевык слова: Островодужный вулканизм, анортит, мегакристы, базальты, ликвидусные фазы.

\section{Compositional features of anorthite megacrysts in lavas of Maly Tigil volcano(Sredinny Range, Kamchatka) as a marker of subduction parameters}

Tolstykh M.L. ${ }^{1}$, Babansky A.D. ${ }^{2}$

${ }^{1}$ Vernadsky Institute of Geochemistry and Analytical Chemistry of Russian Academy of Sciences (GEOKHI RAS)

${ }^{2}$ Institute of Geology of Ore Deposits, Petrography, Mineralogy and Geochemistry (IGEM) RAS

\begin{abstract}
Anorthite megacrysts up to $25 \mathrm{~mm}$ in size were discovered in the altered lavas of the Maly Tigil massif (Sredinny Range, Kamchatka). Their trace element compositionsprovide evidence on the geodynamic conditions of their formation. The depth of the surface of the subducting plate is $\sim 150 \mathrm{~km}$. The obtained data indicatethat the rockswere formed during the Neogene stage of volcanism in the Sredinny Range of Kamchatka, when the subduction front occurred west of its present position.
\end{abstract}

Keywords: Island arc, volcano, anorthite, megacryst, liquidus phases.

Срединный хребет Камчатки (CX) - крупнейшая вулкано-тектоническая структура п-ва Камчатка, состоящая из древнего (мел-палеоген) метаморфического массива и вулканического пояса, сформировавшегося в неоген-четвертичное (N-Q) время. Ранние $(\mathrm{N})$ вулканические породыСрединного хребта характеризуются геохимическими особенностями, типичными для вулканитов фронтальных зон островных дуг, в частности, дефицитом HFSE. Породы четвертичного возраста СX могут быть отнесены к породам гибридного типа из-за сочетания в них геохимических признаков островодужного и внутриплитного происхождения, что объясняется довольно резкой сменой геотектонического режима магмогенерации в позднем неогене(Авдейко, 2006, Волынец, 2017). НепрерывностьвулканическойактивностирайонаСрединногохребтачастоявляетсяпричинойсильныхвторичныхизмененийболеедревних пород в зонах повторной термальной проработки, что затрудняет определение исходных геохимических характеристик пород, а также изотопное датирование вулканитов. В этих случаях проблема поиска косвенных петрогенетических маркеров для относительно древних пород стоит особенно остро.

В рамках изучения миоцен-четвертичного вулканизма Срединного хребта (CX) Камчатки летом 2019 года нашей рабочей группой были опробованы лавы в массивах гор Большой и Малый Тигиль (рис. 1). Гора Малый Тигиль расположена близ разломной зоны, обусловившей сильные вторичные изменения вулканитов. Этот эруптивный центр, предположительно соответствующий стадии неогенового вулканизма, состоит из нескольких крупных лавовых горизонтов.

В основании лавовой толщи Малого Тигиля лежит слой хлоритизированных оливиновых базальтов, которые отличает наличие мегакристов плагиоклаза - почти изометричных темноокрашен- 


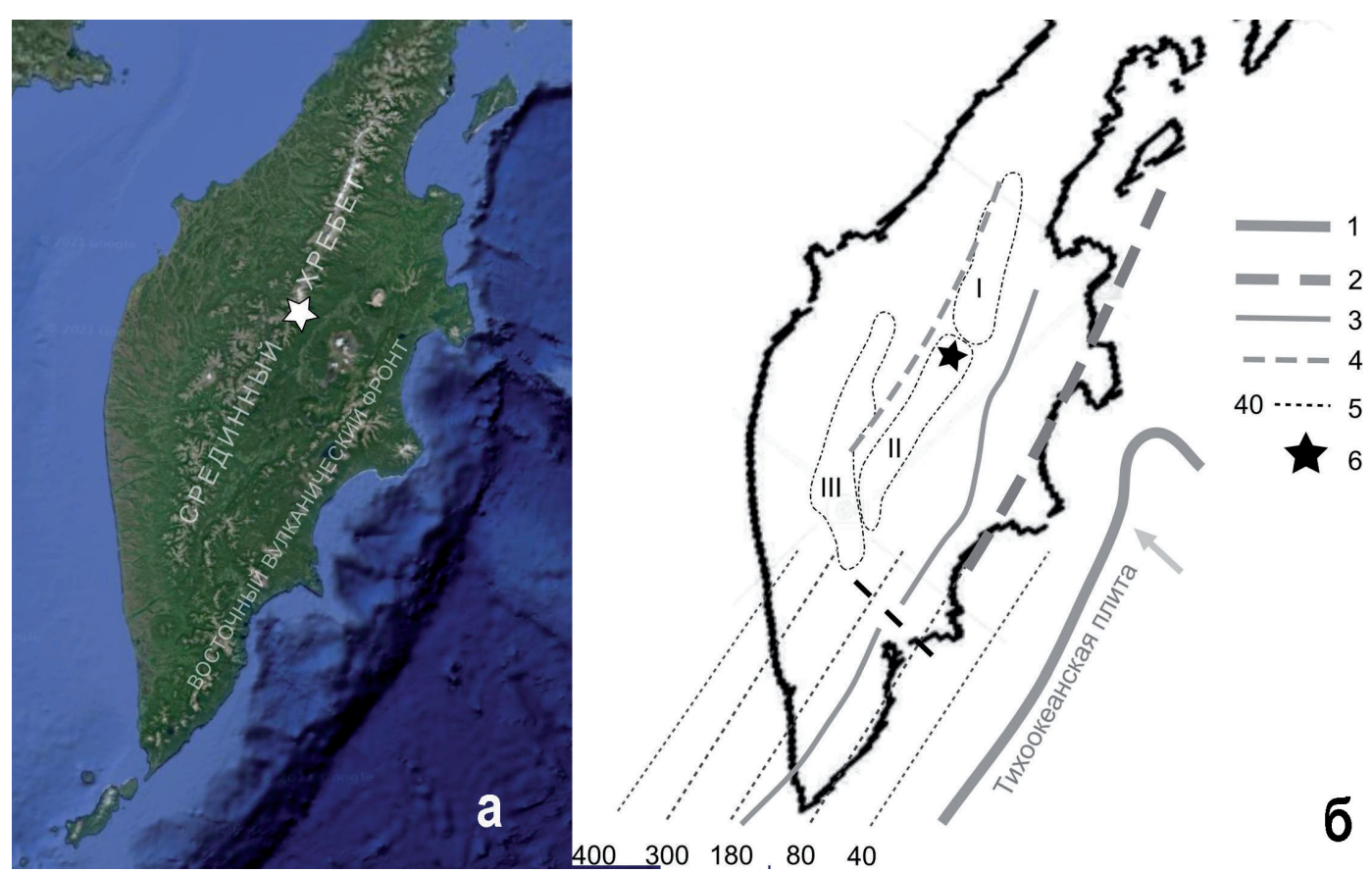

Рис. 1. Полуостров Камчатка: а) спутниковый снимок и б) тектоническая схема.

I - северная, II, III - юго-восточная и юго-западная ветви СX. Расположение глубоководного желоба и осевой зоны вулканического пояса островных дуг: 1, 3 - современной; 2, 4 - неогенового времени по (Леглер, 1977); 5 - глубины (км) докровли погружающейся Тихоокеанской плиты, по (Gorbatovetal., 1997); 6 - влк. Малый Тигиль.

Fig. 1. Kamchatka Peninsula: a)satellite image;b)tectonic scheme.

I - N; II, III - SE, SW branches of the Sredinny Range. The location of the deep-water trough and the axial zone of the volcanic belt of the island arcs: 1, 3 - modern; 2, 4-Neogenic time (Legler, 1977); 5 - depth (km) to the roof of the Pacific plate, according to (Gorbatov et al., 1997); 6 - Maly Tigil.

ных шестиугольных зерен размером до 2.5 см. (рис. 2). В мегакристах многда встречаются кристаллические включения оливина Fo 78 и ортопироксена En 73. Остальные вкрапленники породы представлены гораздо более мелкими реликтами оливина Fo 78-73 и пироксеновFs 30-40 En 70-55 Wo 4-5 и Fs 15 En 45 Wo40 в сростках с титаномагнетитом.

Особенностью мегакристов плагиоклаза (P1) является практически полное отсутствие зональности и стабильность состава анортита An91-93 (табл. 1); по составу отличается только достаточно узкая кайма An 66-68 с признаками резорбции и расплавных микровключений. Также характерной чертой мегакристов можно считать чрезвычайно низкие концентрации $\mathrm{K}_{2} \mathrm{O}(<0.1$ мас. \%). К сожалению, ядра мегакристов не содержат расплавных включений, поэтому напрямую оценить составы минералообразующего расплава не представляется возможным.

Подобные незональные мегакристы анортитового состава, широко распространенные в островодужных лавах наряду с оливином, расцениваются как ранние ликвидусные фазы, равновесные с высокоглиноземистым расплавом, сформированным при частичном плавлении материала мантийного клина (Kimata et al., 1995). Возможность образования ликвидусного анортита в примитивных расплавах с содержаниями $\mathrm{MgO}$ 7-9 мас. \% и относительно высокими содержаниями $\mathrm{H}_{2} \mathrm{O}$ (до 3 мас. \%) на глубинах 5-8 км была доказана как посредством петрологического моделирования (Bindeman, Baily, 1999), так и экспериментально (Бабанский и др., 1987, Panjasawatwongetal., 1995). Наряду с анортитом к наиболее ранним фазам может быть отнесен оливин Fo 75-80.Косвенным подтверждением именно такого порядка кристаллизации $(\mathrm{Ol}+\mathrm{An})$ в породах влк. Малый Тигиль могут служить кристаллические включения Fo 78 в мегакристах анортита, а также отсутствие среди кристаллических включений в мегакристах клинопироксена, который мог бы препятствовать появлению анортита на ликвидусе. 

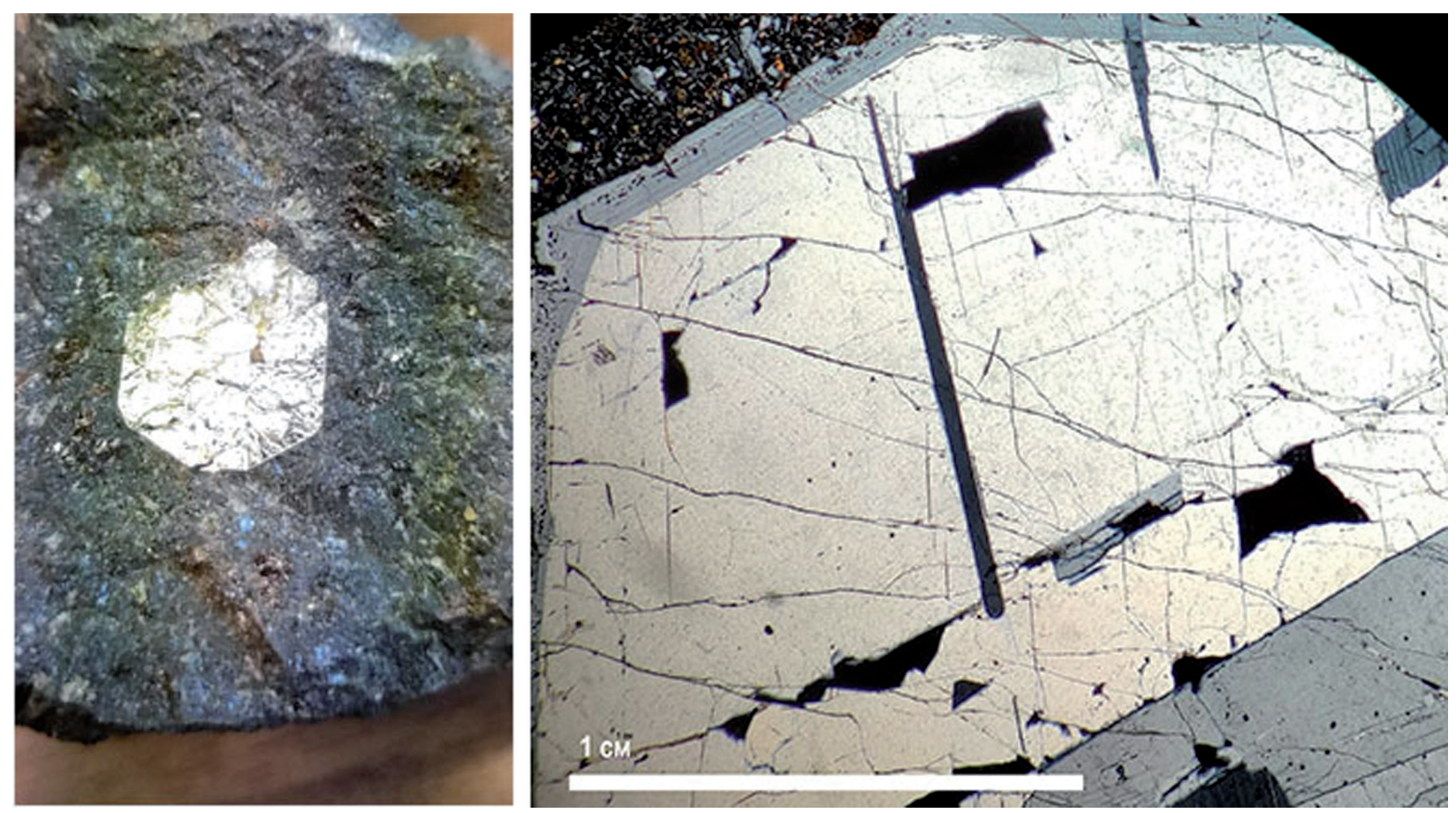

Рис. 2. Мегакристы плагиоклаза (справа - под микроскопом в скрещенных николях).

Fig. 2. Megacrysts of plagioclase (right - under a microscope).

Таблица 1. Представительные составы плагиоклаза мегакристов центра Малый Тигиль.

Table 1. Representative compositions of P1 megacrysts of the Maly Tigil volcanic center.

\begin{tabular}{|l|l|l|l|l|l|l|l|l|l|l|l|}
\hline № $\mathrm{\Pi} / \Pi$ & \multicolumn{1}{|c|}{1} & \multicolumn{1}{|c|}{2} & \multicolumn{1}{|c|}{3} & \multicolumn{1}{c|}{4} & \multicolumn{1}{c|}{5} & \multicolumn{1}{c|}{6} & \multicolumn{1}{c|}{7} & \multicolumn{1}{c|}{8} & \multicolumn{1}{c|}{9} & \multicolumn{1}{c|}{10} & \multicolumn{1}{c|}{11} \\
\hline $\mathrm{SiO}_{2}$ & 43.50 & 43.61 & 43.32 & 43.31 & 50.14 & 50.63 & 43.41 & 43.64 & 43.86 & 49.25 & 49.94 \\
\hline $\mathrm{TiO}_{2}$ & 0.00 & 0.02 & 0.03 & 0.03 & 0.04 & 0.00 & 0.05 & 0.06 & 0.04 & 0.01 & 0.08 \\
\hline $\mathrm{Al}_{2} \mathrm{O}_{3}$ & 36.97 & 36.86 & 37.21 & 37.02 & 32.01 & 31.58 & 36.88 & 36.67 & 36.66 & 32.27 & 31.71 \\
\hline $\mathrm{FeO}$ & 0.47 & 0.40 & 0.48 & 0.47 & 0.57 & 0.73 & 0.52 & 0.66 & 0.54 & 0.83 & 0.71 \\
\hline $\mathrm{MnO}$ & 0.01 & 0.05 & 0.08 & 0.02 & 0.08 & 0.08 & 0.06 & 0.08 & 0.00 & 0.03 & 0.01 \\
\hline $\mathrm{MgO}$ & 0.05 & 0.06 & 0.06 & 0.07 & 0.09 & 0.06 & 0.05 & 0.05 & 0.08 & 0.11 & 0.12 \\
\hline $\mathrm{CaO}$ & 17.68 & 17.81 & 17.64 & 17.72 & 12.64 & 12.28 & 17.91 & 17.75 & 17.63 & 13.87 & 13.15 \\
\hline $\mathrm{Na}_{2} \mathrm{O}$ & 0.88 & 0.89 & 0.80 & 0.99 & 4.04 & 4.18 & 0.88 & 0.96 & 1.01 & 3.29 & 3.96 \\
\hline $\mathrm{K}_{2} \mathrm{O}$ & 0.02 & 0.02 & 0.03 & 0.04 & 0.14 & 0.16 & 0.04 & 0.06 & 0.04 & 0.12 & 0.17 \\
\hline & 100 & 100.0 & 100.0 & 100.0 & 100.0 & 100.0 & 100.0 & 100.0 & 100.0 & 100.0 & 100.0 \\
\hline $\mathrm{An}$ & 92 & 92 & 92 & 91 & 63 & 61 & 92 & 91 & 90 & 69 & 64 \\
\hline $\mathrm{Ab}$ & 8 & 8 & 8 & 9 & 36 & 38 & 8 & 9 & 9 & 30 & 35 \\
\hline $\mathrm{Ort}$ & 0 & 0 & 0 & 0 & 1 & 1 & 0 & 0 & 0 & 1 & 1 \\
\hline
\end{tabular}

Примечание. 1-6, 7-11 - профили центр-край двух зерен анортита по данным микроанализатора CamecaSX-100 (ГЕОХИ РАН); 5, 6, 10, 11 - составы кайм мегакристов.

Редкоэлементный состав мегакристов можно считать «реликтовым» из-за низких скоростей диффузии микроэлементов в плагиоклазах с высокой долей анортита (Giletti, 1995); следовательно, можно предполагать, что дальнейшие петрогенетические процессы, в которые были вовлечены изучаемые мегакристы, не могли существенно повлиять на содержания компонентов REE и HFSE. Содержания элементов-примесей в анортитах вулканического центра Малый Тигиль представлены в таблице 2.

Микроэлементный составмегакристов анортита в островодужных породах зависит от множества параметров, среди которых - состав мантийного субстрата, степень его плавления, водонасыщенность результирующего расплава, косвенно связанные с удаленностью вулканического 
центра от фронтального желоба островной дуги и с глубинойсейсмо-фокальной зоны (СФЗ) под вулканом(Panjasawatwongetal., 1995).

Таблица 2. Микроэлементный состав (ppm)мегакристов анортита.

Table 2. Trace elements composition of Pl megacrysts.

\begin{tabular}{|c|c|c|c|c|c|c|}
\hline Эл-т/ $\mathrm{N}_{\text {п/п }}$ & 1 & 2 & 3 & 4 & 5 & 6 \\
\hline $\mathrm{P}$ & 16.40 & 20.50 & 32.79 & - & 29.86 & - \\
\hline $\mathrm{K}$ & 1680 & 6094 & 1016 & 1610 & 1106 & 1493 \\
\hline $\mathrm{Ti}$ & 69.1 & 49.8 & 49.1 & 61.0 & 72.4 & 202.5 \\
\hline $\mathrm{Co}$ & 3.90 & 4.19 & 4.18 & 4.03 & 4.48 & 3.35 \\
\hline $\mathrm{Sr}$ & 603 & 621 & 604 & 602 & 665 & 628 \\
\hline $\mathrm{Zr}$ & 0.20 & 0.28 & 0.23 & 0.22 & 0.17 & 0.13 \\
\hline $\mathrm{Nb}$ & 0.02 & 0.04 & 0.02 & 0.01 & 0.03 & 0.01 \\
\hline $\mathrm{Cs}$ & 0.00 & 0.01 & 0.00 & 0.00 & 0.00 & 0.03 \\
\hline $\mathrm{Ba}$ & 25.8 & 20.3 & 21.5 & 24.9 & 26.5 & 93.8 \\
\hline $\mathrm{Y}$ & 0.19 & 0.33 & 0.39 & 0.19 & 0.17 & 0.29 \\
\hline $\mathrm{La}$ & 0.29 & 0.23 & 0.24 & 0.27 & 0.33 & 0.71 \\
\hline $\mathrm{Ce}$ & 0.55 & 0.42 & 0.43 & 0.56 & 0.66 & 1.48 \\
\hline $\mathrm{Sm}$ & 0.06 & 0.06 & 0.07 & 0.09 & 0.10 & 0.14 \\
\hline $\mathrm{Eu}$ & 0.15 & 0.16 & 0.13 & 0.16 & 0.14 & 0.35 \\
\hline $\mathrm{Gd}$ & 0.48 & 0.04 & 0.12 & 0.05 & 0.12 & 0.17 \\
\hline $\mathrm{Dy}$ & 0.03 & 0.01 & 0.02 & 0.03 & 0.03 & 0.08 \\
\hline $\mathrm{Li}$ & 0.76 & 0.07 & 0.01 & 0.00 & 0.29 & 0.42 \\
\hline $\mathrm{B}$ & 0.05 & 0.08 & 0.09 & 0.10 & 0.06 & 0.32 \\
\hline $\mathrm{Be}$ & 0.10 & 0.15 & 0.23 & 0.31 & 0.22 & 0.55 \\
\hline
\end{tabular}

Примечание. 1-5 - центральные зоны вкрапленников; 6 - кайма. Данные полученыметодом вторично-ионной масс-спектрометрии (SIMS) для определения редких элементов в стеклах (Cameca IMS-4f, Центр Коллективного пользования «Диагностика микро- и макроструктур», г. Ярославль.

Корреляция содержаний микроэлементов в анортите и глубины СФЗ, соответствующей вулканическому центру, была эмпирически выявлена, в частности, при исследовании серии образцов мегакристов, отобранных в лавах более чем 10 эруптивных центров Курильской островной дуги, в т.ч. и подводных(Bindeman, Baily, 1999). В силу сходства геодинамических обстановок Камчатки и Курил (Авдейко, 2006) можно предполагать, что для вулканов Камчатского полуострова некоторые из этих закономерностей могут оказаться актуальными.

При сравнениимикроэлементныххарактеристик мегакристов анортита вулкана Малый Тигиль с данными по мегакристам курильских вулканов (рис. 3) было выявлено совпадение диапазонов значений для большинства элементов (за исключением калия). Интервал глубин СФЗ, соответствующий полученным значениям содержаний различных микроэлементов, соответствует 140-160 км в том числе и для элементов, концентрации которых характеризуются минимальной дисперсией (Sr, Ba). И так, если считать закономерности, выведенные в (Bindeman, Baily, 1999), корректными для Камчатки, то глубины кровли субдуцирующей плиты под вулканом во время формирования изучаемого парагенезиса соответствовали, в среднем, 150 км. На современной тектонической схеме Камчатки (рис. 1 б) область Срединного хребта маркируется линиями глубин 300-400 км. В то же время в неогене фронт субдукции располагался западнее современного (Леглер, 1977), и глубины СФЗ в районе Малого Тигиля могли соответствовать полученным значениям.Таким образом, особенности состава мегакристов анортита в измененных породах вулкана Малый Тигиль позволяют предполагать их формирование из первичных выплавок мантийного клина при глубине СФЗ около 150 км, что может свидетельствовать об относительной древности этих пород, поскольку такие параметры субдукции были характерны для некоторых зон Срединного хребта в неогене. 

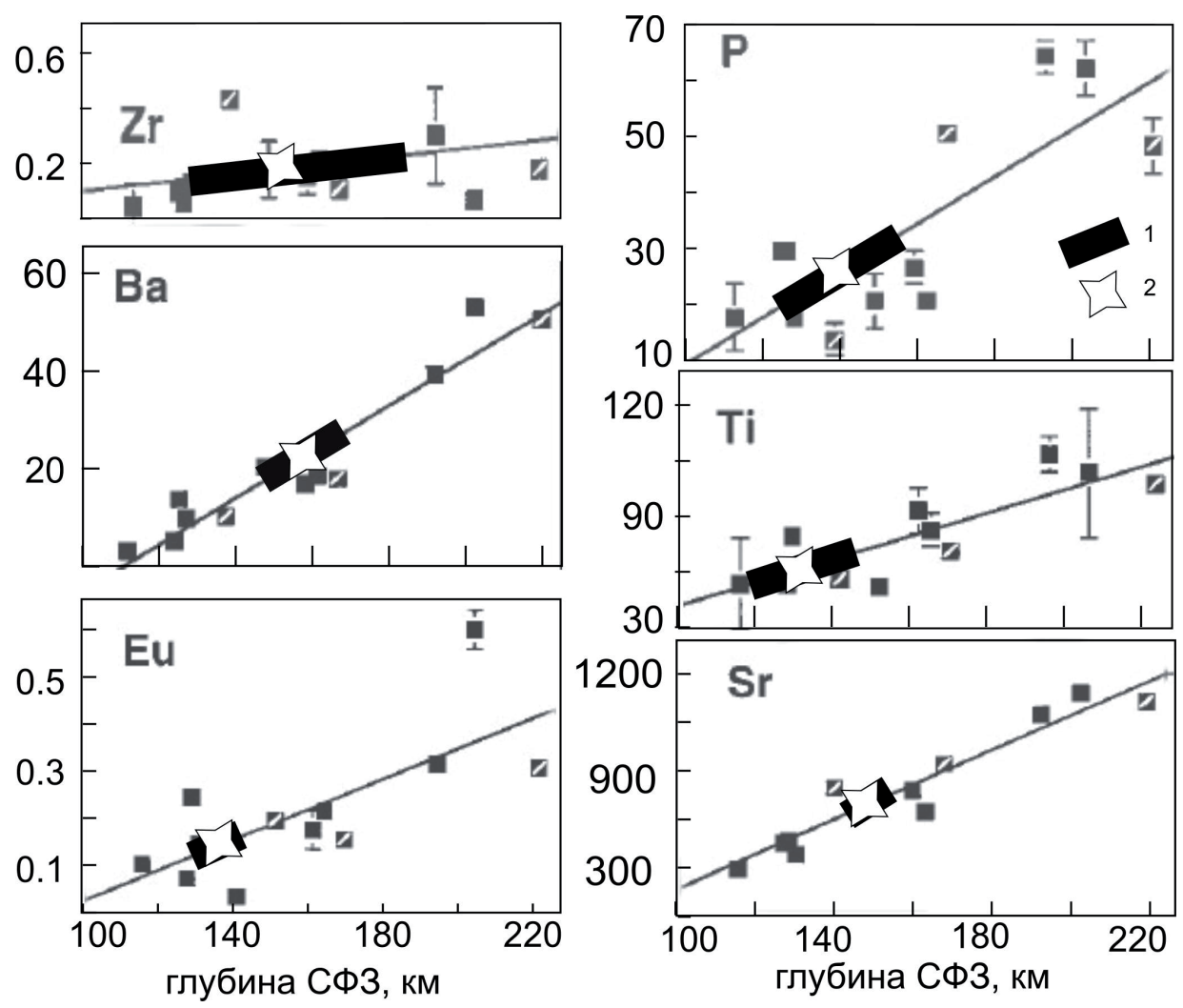

Рис. 3. Содержания микроэлементов в мегакристах вулканического центра Малый Тигиль (1 - весь диапазон, 2 - усредненные значения) в сравнении с данными (Bindeman, Baily, 1995).

Fig. 3. Trace elements composition of Pl megacrysts of the Maly Tigil volcanic center ( 1 - the entire range, 2 - the average values) in comparison with the data (Bindeman, Baily, 1995).

Работа выполнена в рамках темы государственного задания0137-2019-0014.

\section{Литература}

1. Авдейко Г.П., Палуева А.А., Хлебородова О.Л. Геодинамические условия вулканизма и магмообразования Курило-Камчатской островодужной системы // Петрология. 2006. Т. 14. № 3. С. 248-266.

2. Бабанский А.Д., Рябчиков И.Д., Богатиков О.А. Эволюция щелочноземельных магм. М. Изд-во: Наука. 1987. $213 \mathrm{c}$.

3. Волынец А.О., Певзнер М.М., Толстых М.Л., Бабанский А.Д. Вулканизм южной части Срединного Хребта Камчатки в неоген-четвертичное время // Геология и геофизика. 2017. Т. 59. № 12. С. 1979-1996. DOI: $10.15372 / \mathrm{GiG} 20181204$.

4. Леглер В.А. Развитие Камчатки в кайнозое с точки зрения теории литосферных плит // Тектоника литосферных плит (источники энергии тектонических процессов и динамика плит). М. Изд-во: Институт океанологии АН СССР. 1977. С. 137-169.

5. Bindeman I.N., Bailey J.C. Trace elements in anorthite megacrysts from the Kurile Island Arc: a window to across-arc geochemical variations in magma compositions // Earth and Planetary Science Letters. 1999. V. 169. P. 209-226.

6. Giletti B.J. Isotopic equilibrium-disequilibrium and diffusion kinetics in feldspars, in: Parsons, I., Feldspars and Their Reactions. 1994. P. 351-382.

7. Gorbatov A., Kostoglodov V., Suárez G., Gordeev E. Seismicity and structure of the Kamchatka subduction zone // J. Geophys. Res. Solid Earth. 1997.V. 102. P. 17883-17898.

8. Kimata M., Nishida N., Shimizu M., Saito S., Matsui T., Arakawa Y. Anorthite megacrysts from island arc basalts // Mineral. Magnet. 1995. V. 9. P. 1-14.

9. Panjasawatwong Y., Danyushevsky L.V., Crawford K.LA.J., Harris. An experimental study of the effects of meltcomposition on lagioclase-melt equilibrium at 5 and 10kbars: implications for the origin of magmatic high-Anplagioclase // Contrib. Mineral Petrol. 1995. V. 118. P. 420-432. 